\title{
Editorial: as medidas tomadas pelo Centro Universitário Internacional Uninter durante a pandemia de COVID-19
}

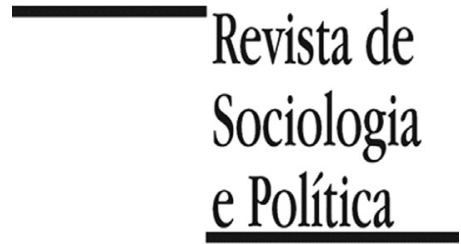

DOI 10.1590/1678-987320287300

\author{
Lucas Massimo' (iD, Benhur Gaio" (iD, \\ Nelson Castanheira"IID, Débora Veneral" iD \\ IRevista de Sociologia e Política, Curitiba, PR, Brasil. \\ ${ }^{\mathrm{II}}$ Centro Universitário Internacional, UNINTER, Curitiba, PR, Brasil.
}

I nformamos aos leitores da Revista de Sociologia e Política que tendo em vista a suspensão de recursos provenientes do governo federal no último ano, a manutenção deste periódico está sendo possível graças ao apoio da iniciativa privada. Agradecemos ao Centro Universitário Internacional Uninter por compreender e incentivar a aplicação de recursos financeiros na comunicação científica.

A suspensão das linhas de financiamento para a comunicação científica possui uma série de efeitos deletérios para a comunidade científica, e nem sempre esses efeitos são conhecidos pelos leitores do nosso acervo. Se por um lado o modelo de acesso aberto e irrestrito possibilita aos leitores o contato com resultados de pesquisas de ponta, por outro lado a publicação em acesso aberto torna os leitores alheios a todos os custos necessários para a produção de um artigo científico. Apenas a diminuta parcela dos autores que têm seus artigos aprovados em revistas de alto impacto na comunidade entende, na prática, a dimensão do trabalho que é realizado pelos comitês editorais, após a conclusão do processo de arbitragem por pareceristas anônimos. A produção propriamente dita dos artigos inclui pelo menos cinco tarefas que precisam ser realizadas após a análise de mérito, são elas: (i) revisão ortográfica, (ii) normalização de referências, (iii) padronização de gráficos, quadros e tabelas, (iv) diagramação e leiaute e (v) marcação em linguagem XML. Essas são as atividades para as quais se destinam os recursos do patrocinador. Feitos esses esclarecimentos, passemos ao teor do nosso documento.

Este editorial tem como objetivo discutir junto aos leitores da Revista de Sociologia e Política algumas das medidas tomadas pelo Centro Universitário Internacional Uninter em face da pandemia. O documento aborda três blocos de ações. Em primeiro lugar, apresentaremos as principais providências acadêmicas adotadas pela instituição em relação aos colaboradores e estudantes durante a pandemia, bem como apresentaremos alguns indicadores que resultaram desses atendimentos. Em um segundo momento, vamos nos dirigir aos impactos que a pandemia provocou sobre as atividades conduzidas no Programa de Iniciação Científica da Uninter. A terceira parte do texto tratará de alguns dos resultados obtidos pela Comissão Própria de Avaliação, que conduziu uma pesquisa com vistas a mensurar a percepção dos estudantes acerca das primeiras medidas tomadas pela instituição, logo no início da pandemia. 
${ }^{1}$ Como se lê no extrato da Ata da reunião extraordinária da Reitoria realizada em 12/03/2020: "Iniciada a sessão, o senhor Reitor saudou a todos e abordou o primeiro item da pauta: COVID-19,
As reuniões com a Reitoria realizadas às segundas-feiras para deliberação das atividades Institucionais e alinhamentos das atividades pedagógicas sempre foram prática costumeira no Centro Universitário Internacional Uninter. No entanto, excepcionalmente, os Diretores acadêmicos foram convocados no dia 12/03/2020 (quinta-feira) para uma sessão em caráter extraordinário ${ }^{1}$. Estávamos diante da pandemia declarada pela Organização Mundial de Saúde OMS, e precisávamos agir com rapidez e cautela para o cumprimento das regras estabelecidas na Lei 13.979, de 6 de fevereiro de 2020, sobre as medidas de enfrentamento da emergência de saúde pública de importância internacional decorrente do coronavírus. Nessa mesma oportunidade "o senhor Reitor aclarou que nesta reunião seriam definidas algumas ações para a prevenção da COVID -19 e que um grupo de trabalho composto de onze pessoas já havia sido organizado para a implementação dessas decisões"

A preocupação inicial da Instituição deu lugar aos colaboradores contemplados no grupo de risco, ou seja, pessoas a partir de 65 anos, pessoas debilitadas ou em tratamento de saúde, tabagistas, portadores de doenças respiratórias e, preventivamente, incluindo-se também as gestantes. E assim seguiu a reunião extraordinária na qual resultou determinado que "os Diretores teriam que, em primeiro lugar, mapear, urgentemente, os colaboradores nessas condições, incluindo-se, também, aqueles que tenham algum doente em casa que seja portador de doença respiratória, os quais deverão seguir realizando suas atividades em casa, home office, e determinou que esse mapeamento deveria estar pronto até o dia seguinte a esta reunião. Em segundo lugar, preparar-se para uma situação mais radical no sentido de os demais colaboradores terem de trabalhar em suas residências, visto que este Centro Universitário tem 250 mil alunos e não poderá haver a descontinuidade das atividades dos alunos, mapeamento que deverá ser feito pelo Diretores e coordenadores de cursos a partir da semana seguinte a esta reunião. E, também, os Diretores deverão fazer esse mesmo mapeamento para os outros colaboradores, caso a doença se agrave e eles precisem fazer seu trabalho em casa, além disso, o senhor Reitor orientou os Diretores a conversarem com essas pessoas e indagarem se elas têm computadores em casa com acesso à Internet e, também, se elas têm condições de segurança para trabalharem em casa, a fim de se evitar possíveis acidentes de trabalho." E assim, foi dado prosseguimento à implementação das atividades em home office para todos os colaboradores da Instituição, perdurando essa situação até dezembro/2020, considerando ainda o cenário pandêmico que vivemos. Aliada à preocupação da proteção dos funcionários, as normativas também foram implementadas nos mais de 700 polos de apoio presencial vinculados ao Centro Universitário Internacional Uninter. Tais medidas foram necessárias tanto para a proteção dos gestores e funcionários dos polos como dos alunos que costumam frequentá-los para realizarem suas atividades acadêmicas, especialmente as provas.

Quanto aos laboratórios (computadores/notebooks) utilizados para a realização das provas, locais de fácil contaminação uma vez que são utilizados por diversas pessoas, em especial no polo de apoio presencial, "o senhor Reitor determinou que seja respeitada a distância de dois (02) metros entre cada máquina, igualmente, deliberou que tanto os computadores individuais como os dos laboratórios, bem como telefones e smartfones deverão passar por um processo de limpeza e desinfecção com álcool gel, o que será de responsabilidade do setor de infraestrutura da instituição, e os demais ambientes deverão ser limpos e desinfetados com hipoclorito 1\%."

As providências precisavam e foram tomadas tanto para as turmas presenciais quanto para os alunos que estudam na EAD. No presencial também foram implementadas ações imediatas por intermédio dos Diretores de Escolas, Coordenadores, Professores envolvendo o Núcleo Docente Estruturante - NDE e 
${ }^{2}$ Registramos nosso singelo agradecimento à Helenice Ramirez Jabur e Alexandre Langowski pela tabulação dos dados sobre as avaliações e pelo detalhamento acerca da CMA. colegiado de cursos, que migraram de inopino os alunos do presencial para o EAD por precaução e segurança, considerando os grupos de risco e, principalmente, evitar qualquer contaminação pelo vírus.

No âmbito da atuação do Centro Universitário Internacional Uninter, a maioria dos estudantes encontra-se vinculada aos cursos ofertados na modalidade EAD. Nesse caso, o principal fator de aglomeração entre os estudantes é a realização das avaliações que até 2019, eram realizadas nos Polos de Apoio Presencial, sob a supervisão da equipe dos polos. Portanto, uma das primeiras medidas preventivas tomadas pela instituição reporta-se à essa situação. Com a pandemia e a declaração de estado de calamidade pública, desde o início de abril, todos os estudantes da Uninter puderam realizar suas provas sem a necessidade de deslocamento seja aos campi da Uninter em Curitiba, ou ainda, aos Polos de Apoio Presencial localizados em todo o território nacional. Para o cumprimento dessa medida, a instituição desenvolveu uma ferramenta que realiza a supervisão das avaliações de modo remoto, ou seja, além de ser necessário câmera/webcam e microfone instalados em um computador ou notebook, os alunos não podem se ausentar da frente da câmera durante a realização da prova, para não prejudicar a análise de imagens e áudios, que possibilitam auditoria nas provas. A Tabela 1 oferece uma dimensão da quantidade de avaliações que foram realizadas por supervisão remota ${ }^{2}$. Desde o início do ano, pouco mais de dois milhões e duzentas mil provas foram feitas sem que os estudantes necessitassem se deslocar aos polos de apoio presencial, preservando assim sua saúde e diminuindo a possibilidade de contaminação com o SARS-CoV-2. No quadro abaixo, é possível inferir o volume de provas realizadas entre abril e novembro de 2020 por meio de supervisão remota.

Os dados fornecidos acima foram compilados pela CMA. A Central de Mediação Acadêmica (CMA) é um órgão suplementar de apoio acadêmico do Centro Universitário Internacional Uninter, criado conforme a Resolução 118/2016 do CEPE na data de 05 de maio de 2016. O setor tem por finalidade realizar o atendimento, acompanhamento e o monitoramento acadêmico dos alunos de graduação, pós-graduação e EJA na modalidade a distância, semipresencial e presencial, objetivando a orientação acadêmica e o consequente controle da evasão. Atualmente, a Central de Mediação Acadêmica é formada por 4 núcleos específicos: Acolhimento, Fidelização, Atendimento Online e Atendimento telefônico. Estruturada com uma equipe multidisciplinar, a CMA possui atualmente 73 integrantes, cuja contribuição tem sido significativa pela diversidade de alunos, em diferentes cursos, atendidos pelo setor. Cada time foi desenvolvido estrategicamente para atender às necessidades específicas do aluno ao longo da vida acadêmica, seja nos primeiros passos ainda como

Tabela 1 - Quantidade de avaliações realizadas em supervisão remota (sem deslocamento aos Polos) por escola superior

\begin{tabular}{lcc}
\hline Setor & Total Provas Únicas & Percentual \\
\hline Escola Superior de Gestão e Negócios & 670.701 & $29 \%$ \\
Escola Superior de Educação & 666.628 & $29 \%$ \\
Escola Superior Politécnica & 285.078 & $12 \%$ \\
Pós-Graduação & 263.075 & $12 \%$ \\
Escola Superior de Gestão Pública, Política e Jurídica & 236.473 & $10 \%$ \\
Escola Superior de Saúde, Meio Ambiente, Sustentabilidade e Humanidades & 162.237 & $7 \%$ \\
Extensão & 35 & $0,00 \%$ \\
Total Geral & 2.284 .227 & $100 \%$ \\
\hline
\end{tabular}

Fonte: Central de Mediação Acadêmica (CMA). 
calouro (acolhimento), na fase de adaptação ou na reta final (fidelização) para a conquista do seu diploma. Neste período de pandemia, os atendimentos se intensificaram, pois, o objetivo da Instituição, em especial, da CMA era dar todo o apoio aos alunos para que em um cenário tão difícil não desistissem dos seus estudos - e foi assim que toda a equipe e os colaboradores foram orientados. Para que possamos ter uma ideia da dimensão e do alcance do trabalho realizado, é imprescindível conhecer cada uma das equipes e suas funções quanto ao atendimento ofertado ao aluno.

A equipe de Acolhimento é responsável pelo acompanhamento dedicado aos nossos ingressantes no ensino superior. Em 2019, foi organizado um segmento dentro do setor composto pela equipe de acolhimento. Passando a incorporar um dos núcleos da CMA, essa equipe atua no acolhimento aos estudantes que estão iniciando os seus estudos (calouros) durante o primeiro módulo, prestando todo o atendimento e orientações necessárias, até que estejam adaptados à rotina acadêmica e ao sistema de ensino do Centro Universitário Internacional Uninter. Após esse período, os alunos passam a ser acompanhados pela equipe de Fidelização, que é a responsável por orientar, incentivar e auxiliar os polos na utilização da ferramenta de fidelização, visando prevenir a evasão dos alunos por meio do acompanhamento e monitoramento do desempenho acadêmico de cada um. Essa equipe também auxilia os Polos em todas as demandas acadêmicas provenientes de cada aluno.

A equipe faz o monitoramento do desempenho e dos acessos dos alunos por meio de uma ferramenta de Fidelização desenvolvida pela equipe do Univirtus vinculada à Pró-reitora de Tecnologia Educacional, na época da sua criação. O sistema fornece informações acerca das situações acadêmicas dos alunos, buscando indicadores críticos quanto ao acesso e às notas dos alunos, colocando-os numa lista de prioridades que geram alertas a serem observados e atendidos pelos polos de apoio presencial e pela equipe da CMA. Para cada indicador é adotada uma ação imediata que visa o apoio e orientação ao estudante, os contatos são tratados por ordem de prioridade, de acordo com o que o próprio sistema sinaliza. Grande parte da tratativa dos alertas se concentra em ligações telefônicas e e-mails, entretanto, há também o envio de mensagens por SMS quando esses outros meios não são eficazes. Após um alerta ser atendido, os estudantes recebem uma mensagem do orientador acadêmico através de um ícone do Univirtus chamado "contatos", ali ele pode manter contato continuamente com a CMA.

A CMA também possui a equipe de atendimento online, que desenvolve um atendimento personalizado para cada aluno em tempo real, por meio de um Chat, desenvolvido para esclarecimento de dúvidas e orientações acadêmicas. Neste atendimento, utiliza-se o software da empresa fornecedora Dígitro, a ferramenta Interact, que por meio de um chatbot (chat robotizado) permite que o estudante pesquise sua dúvida por meio de palavras-chave, interagindo com diversos assuntos cadastrados na plataforma. Se o estudante preferir, também pode optar por conversar diretamente com um assistente de operações acadêmicas da CMA, o qual intitulamos chat convencional. Finalmente, o quarto componente é a equipe de Atendimento 0800: Em setembro de 2019, o atendimento ao aluno via 0800 passa a ser realizado sob orientações da gerência da CMA, tornando o setor como a principal frente de orientação acadêmica ao estudante do Centro Universitário Internacional Uninter.

Entre as principais atribuições da CMA, destacam-se as seguintes incumbências: 
I. Orientar, motivar e mediar a utilização dos recursos de aprendizagem oferecidos, fornecendo apoio e promovendo a manutenção e a satisfação do estudante UNINTER;

II. Acompanhar os acessos e o desempenho dos estudantes no Univirtus, com ações específicas aos ingressantes, estabelecendo os primeiros contatos de acolhimento e orientando os estudos, conforme a necessidade;

III. Acompanhar os acessos e desempenho dos demais estudantes, em adaptação e veteranos, mantendo informados os responsáveis pelos polos de apoio presencial, escolas superiores e coordenação do curso, quanto aos estudantes em estado de alerta, orientando-os e mediando o contato entre ambos;

IV. Motivar os estudantes, calouros, em adaptação ou veteranos, conforme a necessidade, orientando sobre cada etapa do percurso acadêmico, aproximando-os da instituição e proporcionando o estabelecimento de um vínculo entre eles;

V. Acompanhar os estudantes do início ao fim do curso, com atenção especial aos ingressantes, auxiliando-os na compreensão quanto às formas de estudar a distância, às ferramentas e à organização necessária para aprender nessa modalidade.

VI. Desenvolver materiais de apoio aos estudantes com conteúdo de orientação acadêmica, sobre os processos e procedimentos acadêmicos, incentivo e orientações aos estudos.

VII. Reorganizar os prazos de atividades de acordo com a rotina de estudos e necessidades individuais de cada estudante, caso haja necessidade, objetivando a permanência.

A Tabela 2 dá uma dimensão da quantidade de atendimentos realizados pelas equipes da CMA entre 01/01/2020 e 30/11/2020, ou seja, durante o período declarado pandêmico e que ainda enfrentamos o COVID-19. O atendimento agregado por canal totaliza pouco menos de 530 mil contatos. Quando nos dirigimos para o atendimento agregado por espécies, foram feitos um pouco menos de três milhões de atendimentos (sendo cerca de um milhão de atendimentos realizados por robôs, e 1,7 milhão de alertas tratados nesse período).

Tabela 2 - Quantidade de atendimentos realizados pela CMA (01/01/2020 e 30/11/2020)

\begin{tabular}{lcc}
\hline Agregação dos atendimentos & Tipo de contato & Quantidade \\
\hline Atendimento agregado por canal & Chat Convencional & 309.153 \\
& Ligações Geradas & 157.995 \\
& Ligações Recebidas & 61.308 \\
Atendimento agregado por & Subtotal & 528.456 \\
espécies & Atendimento robô & 1.032 .437 \\
& Alertas tratados & 1.796 .703 \\
& Liberação de APOL & 43.587 \\
& Contatos respondidos CMA & 55.095 \\
& Solicitações recebidas - CMA & 39.195 \\
& Subtotal & 2.967 .017 \\
\hline
\end{tabular}

Fonte: Central de Mediação Acadêmica (CMA). 
${ }^{3}$ A apresentação do PIC e os editais podem ser consultados em

https://www.uninter.com/pesq uisa/programa-de-iniciacao-cie ntifica-pic/https://www.uninter .com/pesquisa/programa-de-in iciacao-cientifica-pic/
Diante dos dados trazidos, é possível refletir sobre a importância da Central de Mediação Acadêmica no atendimento ao aluno, tornando cada vez mais os processos humanizados, não obstante o uso da tecnologia. Em especial, neste atípico 2020 em que vivemos um ano de adaptações em diversas áreas, dentre elas, a educação, verificamos que é possível, com planejamento, organização e uma equipe devidamente capacitada, atender adequadamente o aluno, orientando-o e dando os encaminhamentos necessários para que ele consiga trilhar sua vida acadêmica.

No Centro Universitário Internacional Uninter nada parou em razão da pandemia, ao contrário, de certa maneira as atividades adquiriram mais velocidade, inclusive aquelas que outrora jamais imaginaríamos que pudessem ser realizadas remotamente. Nesta seara encontra-se a pesquisa científica.

Vejamos então como as dinâmicas da pesquisa científica foram impactadas pela pandemia. Em março de 2020 a Coordenação de Pesquisa e Publicações Acadêmicas da Uninter publicou o edital nº4/2020, com a homologação de alunos bolsistas e voluntários dos Projetos de Iniciação Científica (PIC). Esse documento contém a relação de 786 jovens pesquisadores que foram selecionados para integrar todas as equipes responsáveis pelos projetos de pesquisa que serão desenvolvidos ao longo de 2020. Esse número refere-se aos jovens pesquisadores que atuam em todos os projetos, incluindo, portanto, os projetos de pós-graduação desenvolvidos no Mestrado em Educação e no Mestrado em Direito. No editorial que publicamos no ano passado (Massimo, Gaio, Veneral e Almeida 2019) procuramos dar destaque para os projetos de pesquisa desenvolvidos em nível de strictu sensu, portanto, agora, vamos nos dirigir apenas aos jovens pesquisadores, ou seja, àqueles que foram recrutados para atuar nos projetos de pesquisa realizados pelos cursos de graduação. Todos os dados que discutiremos a seguir estão disponíveis para consulta pública nas páginas da coordenação de pesquisa ${ }^{3}$.

Ao mensurar as informações que constam no edital nº4/2020, encontramos os nomes de 54 docentes, que são responsáveis por 70 projetos de pesquisa. Esses projetos estão agrupados em 24 linhas de pesquisa, que fazem parte de 8 grupos de pesquisa, todos registrados no CNPq. O edital revela ainda que em 2020 existem 504 pesquisadores vinculados aos setenta projetos de pesquisa contando apenas os projetos coordenados por docentes que atuam em cursos de graduação. O mesmo estudante pode participar em mais de um projeto de pesquisa, e para dimensionar essa situação, apresentamos na Tabela 3 a população de jovens pesquisadores envolvidos com atividades de pesquisa. Essa população é composta por 433 jovens pesquisadores, e a maior parte deles (87\%) está vinculada a apenas um projeto de pesquisa. Entre os demais, há 42 estudantes atuando em dois projetos, 10 estudantes trabalhando em três projetos, e 3 alunos que atuam em quatro projetos.

Tabela 3 - População de jovens pesquisadores e quantidade de projetos de pesquisa (apenas estudantes de graduação)

\begin{tabular}{lcc}
\hline $\begin{array}{l}\text { Quantidade de projetos aos quais os } \\
\text { jovens pesquisadores estão vinculados }\end{array}$ & $\begin{array}{c}\text { Total de } \\
\text { indivíduos }\end{array}$ & Percentual \\
\hline Alunos vinculados a apenas 1 projeto & 378 & $87 \%$ \\
Alunos vinculados a 2 projetos & 42 & $10 \%$ \\
Alunos vinculados a 3 projetos & 10 & $2 \%$ \\
Alunos vinculados a 4 projetos & 3 & $1 \%$ \\
Total & 433 & $100 \%$ \\
\hline
\end{tabular}

Fonte: Coordenação de pesquisa (http://uninter.com/pesquisa). 
${ }^{4}$ As informações sobre o PPD também estão disponíveis para consulta pública, neste endereço https://www.uninter.com/pesq uisa/programa-de-pesquisa-do cente-ppd/

5 "O Grupo de Pesquisa é entendido como um conjunto de indivíduos organizados hierarquicamente em torno de uma ou, eventualmente, duas lideranças, cuja experiência e destaque no terreno científico ou tecnológico lhe conferem tal condição". O artigo segundo da RESOLUÇÃO N 12/2012 - CEPE também explica que "O Grupo de Pesquisa terá como líder, obrigatoriamente, um professor doutor com liderança acadêmica e intelectual no seu ambiente de pesquisa e experiência de investigação no terreno científico ou tecnológico". 6 "A Linha de Pesquisa é constituída por temas que unem estudos científicos e que têm como base uma tradição investigativa, havendo afinidade na produção desse resultado. A Linha de Pesquisa, que será coordenada por um pesquisador com titulação mínima de doutor, é subordinada ao Grupo, assim, cada Grupo pode ter uma ou mais Linhas de Pesquisa."
Vejamos agora como ocorre o processo de recrutamento deste pessoal. Todas as atividades do PIC são um desdobramento do Programa de Pesquisa Docente - PPD, que foi instaurado em 2012, por meio da Resolução n ${ }^{\circ}$ 12/2012 do Conselho de Ensino, Pesquisa e Extensão do Centro Universitário Internacional Uninter. A resolução que institui o PPD é bem detalhada ${ }^{4}$, ela determina como devem estar configurados os grupos de pesquisa ${ }^{5}$, e oferece definições específicas acerca do que é um grupo de pesquisa e sobre o que são as linhas de pesquisa $^{6}$. As linhas oferecem o "referencial epistemológico que serve de base para as propostas de projetos de pesquisa", e é por meio destes projetos que ocorre a seleção dos jovens pesquisadores que ingressam no PIC. Como lemos no artigo quinto desta resolução "O ingresso na pesquisa ocorre por meio de um Projeto, com um plano de orientação conforme o modelo adotado pela Coordenação de Pesquisa e que deve apresentar, basicamente, os seguintes elementos: definição do objeto de pesquisa; apresentação dos objetivos; hipótese; revisão bibliográfica; metodologia e referências".

Portanto, o processo de recrutamento se inicia com a iniciativa dos docentes, que apresentam seus projetos para apreciação do Conselho de Pesquisa, cujas atribuições também são especificadas na Resolução no 12/2012 do CEPE. Como lemos no artigo onze desta resolução, compete ao conselho de pesquisa "Emitir parecer sobre os novos projetos de pesquisa", "Analisar relatórios parciais e finais de pesquisa apresentados pelos pesquisadores em formulário próprio, emitindo parecer favorável, ou favorável com ressalvas.”.

Os projetos aprovados pelo Conselho de Pesquisa são divulgados em um edital próprio (no caso em tela, trata-se do edital 01/2020), que contém os títulos de todos os grupos, linhas e projetos de pesquisa aprovados, além dos nomes de todos os coordenadores dos projetos, bem como seus e-mails de contato. Esse documento fica anexado no edital 02/2020, que determina as regras para o processo de seleção. Os alunos interessados em participar do PIC devem entrar em contato com o coordenador do projeto, e cabe a esse docente realizar a seleção dos candidatos, bem como indicar os estudantes que devem ser beneficiados por bolsas de estudos.

Esse é o procedimento de recrutamento dos jovens pesquisadores. A demanda dos estudantes de graduação pelo engajamento em atividades de pesquisa fica bem clara quando mensuramos o contingente de estudantes que ingressaram no PIC. Como podemos constatar no edital $\mathrm{n}^{\circ} 04 / 2020$, a maioria desses alunos exerce a atividade de pesquisa na condição de voluntário. São 440 pesquisadores voluntários e 64 estudantes bolsistas. O edital revela que existem 26 jovens pesquisadores beneficiados com bolsas integrais (que cobrem 100\% da mensalidade) e 38 estudantes beneficiados por bolsas parciais (que cobre $50 \%$ da mensalidade de seus cursos).

$\mathrm{O}$ vínculo dos jovens pesquisadores com as atividades de pesquisa ocorre por intermédio do trabalho desenvolvido pelos coordenadores dos projetos. Os 504 estudantes de graduação selecionados para o PIC em 2020 são acompanhados por 26 professores com titulação de mestrado e 28 professores com titulação de doutorado. Os dados por Escola Superior estão dispostos na Tabela 4.

Os dados presentes na Tabela 4 revelam que duas escolas (ESE e ESSBMAH) concentram a maior parte dos alunos vinculados ao PIC, são 111 estudantes (22\%) de cursos da ESE e 222 estudantes (44\%). Essa concentração não é fortuita. Os projetos de pesquisa desenvolvidos no Centro Universitário Internacional Uninter possuem em seu horizonte a transformação dos contextos locais e a interação com os sujeitos de pesquisa. Essa é uma orientação genérica que se aplica a todos os envolvidos com atividades de pesquisa, mas ela acaba sendo favorecida pelos docentes e estudantes que atuam em cursos de graduação nas áreas de saúde e de educação. 
Tabela 4 - Números absolutos do PIC (grupos, linhas, projetos de pesquisa, docentes e alunos), por Escola Superior (apenas estudantes e professores de cursos de graduação)

\begin{tabular}{|c|c|c|c|c|c|c|c|c|c|}
\hline Nome da escola & Grupos & Linhas & Projetos & $\begin{array}{c}\text { Professores com } \\
\text { mestrado* }\end{array}$ & $\begin{array}{c}\text { Professores com } \\
\text { doutorado* }\end{array}$ & $\begin{array}{c}\text { Alunos } \\
\text { voluntários }\end{array}$ & $\begin{array}{c}\text { Alunos } \\
\text { Bolsistas }\end{array}$ & Soma alunos & $\begin{array}{c}\text { Soma } \\
\text { professores }\end{array}$ \\
\hline $\begin{array}{l}\text { Escola Superior Politécnica } \\
\text { (ESP) }\end{array}$ & 1 & 4 & 18 & 9 & 3 & 52 & 7 & 59 & 12 \\
\hline $\begin{array}{l}\text { Escola Superior de } \\
\text { Saúde, Biociências, Sustenta } \\
\text { bilidade e Humanidades } \\
\text { (ESSBMAH) }\end{array}$ & 2 & 5 & 17 & 9 & 5 & 197 & 25 & 222 & 14 \\
\hline $\begin{array}{l}\text { Escola Superior de } \\
\text { Gestão, Comunicação e } \\
\text { Negócios (ESGCN) }\end{array}$ & 2 & 6 & 15 & 4 & 9 & 64 & 8 & 72 & 13 \\
\hline $\begin{array}{l}\text { Escola Superior de Educação } \\
\text { (ESE) }\end{array}$ & 2 & 7 & 12 & 2 & 6 & 96 & 15 & 111 & 8 \\
\hline $\begin{array}{l}\text { Escola Superior de Gestão } \\
\text { Pública, Política, Jurídica e } \\
\text { Segurança (ESGPPJS) }\end{array}$ & 1 & 2 & 8 & 2 & 5 & 31 & 9 & 40 & 7 \\
\hline Total & 8 & 24 & 70 & 26 & 28 & 440 & 64 & 504 & 54 \\
\hline
\end{tabular}

Fonte: Coordenação de pesquisa (http://uninter.com/pesquisa).

* Esses são os professores incumbidos de coordenar os projetos de pesquisa. 
Esse balanço dá uma dimensão do Programa de Iniciação Científica do Centro Universitário Internacional Uninter em 2020. A partir de agora podemos nos dirigir aos impactos decorrentes da pandemia sobre as rotinas da pesquisa.

Para compreender esse aspecto partimos do protagonismo que o Centro Universitário Internacional Uninter desempenha no Ensino a Distância. Há dois recursos essenciais para quem se engaja na iniciação científica, as bibliotecas virtuais e o Ambiente Virtual de Aprendizagem (AVA). Os acervos das bibliotecas virtuais são vastíssimos e podem ser atualizados com frequência. Em que pese as dificuldades de leitura por meios eletrônicos, os jovens pesquisadores podem se valer de títulos de muitas áreas de conhecimento. Além disso, as bibliotecas virtuais disponibilizam aos leitores ferramentas que ajudam a organizar notas de leitura e fichamentos, e esse tipo de recurso pode ser especialmente oportuno quando o trabalho é realizado coletivamente. $\mathrm{O}$ segundo recurso é o AVA Univirtus. Cada projeto de pesquisa possui uma sala no Ambiente Virtual de Aprendizagem, e os coordenadores de projetos podem alimentar essas salas com rotas de aprendizagem de qualquer curso do Centro Universitário Internacional Uninter. As rotas de aprendizagem de todas as disciplinas oferecidas no EAD da Uninter contêm videoaulas, textos de aprofundamento, indicações de como colocar o conteúdo "na prática" (esse é o nome de uma das seções que está presente em todas as aulas). Cada sala do Univirtus possui um "link tutoria", por meio do qual os estudantes podem enviar dúvidas aos professores que coordenam os projetos de pesquisa, e há um registro detalhado desta correspondência, que possibilita aos gestores acompanharem com precisão qual é o tempo de resposta às dúvidas postadas pelos estudantes. Junto com o link tutoria, as salas do Univirtus também são equipadas com um Fórum, por meio do qual os estudantes podem interagir uns com os outros. Os professores podem utilizar os Fóruns, postar textos estimuladores e podem moderar a interação entre os estudantes. Além disso, a Uninter possui uma plataforma própria para conferências, o Univirtus Reuni, que possibilita a gravação das conferências, e esses vídeos também podem ser postados em suas salas.

Enfim, a diversidade de recursos e ferramentas que as plataformas oferecem são de tal ordem que os alunos ingressantes precisam de algumas semanas apenas para se familiarizar com o Ambiente Virtual de Aprendizagem. Todos esses recursos seriam rigorosamente inúteis se não levarmos em conta alguns valores que orientam a conduta dos professores e estudantes que trabalham

7 As informações que traremos ao leitor foram compiladas com base na exposição de colegas a quem registramos nosso sincero agradecimento. As professoras Desiré Luciane Dominscheck, Kátia Soares e Ivana Busato compuseram junto com os professores Luis Fernando Lopes e Márcio Baroncini Proença a mesa virtual do "VI Seminário de Pesquisadores: as estratégias de pesquisa na pandemia Coordenação de Pesquisa". A atividade foi organizada pela Coordenação de Pesquisa e transmitida em mídias sociais no dia 28/10/2020. A versão integral desta atividade está disponível em

https://youtu.be/rdBOTp6brUE. nessas plataformas. Esse ponto requer um pouco mais de atenção ${ }^{7}$.

A pandemia de Covid-19 ressaltou a relevância das competências digitais para a formação de professores e alunos. Essa terrível circunstância tornou mais intensa as potencialidades do uso da tecnologia no campo educacional. Estamos nos referindo a tecnologias já existentes há muitos anos, mas foi no contexto da pandemia que milhares de profissionais se viram obrigados a transpor para meios virtuais suas reuniões, suas aulas, além é claro do compartilhamento de textos, documentos, bases de dados, entre outros insumos indispensáveis tanto para a iniciação científica como para as rotinas educacionais de um modo mais geral. No caso da Uninter, essa transição foi menos onerosa, uma vez que antes da pandemia os profissionais já estavam habituados a trabalhar nessas condições.

A iniciação científica é um importante espaço para a socialização dos estudantes de graduação em alguns códigos próprios do universo acadêmico ${ }^{8}$. Por meio do PIC, os estudantes aprendem a fazer referências bibliográficas, a realizar leituras dirigidas (ou seja, uma leitura orientada para delimitar problemas teóricos, precisões conceituais, objetivos e metodologias), a navegar por repositórios virtuais (como é o caso da coleção SciELO), além daquelas tarefas 
${ }^{8}$ De modo a atender demandas que apareceram durante a pandemia, a coordenação de pesquisa realizou (também por meios virtuais) um seminário para orientar os estudantes a criar e atualizar currículos na plataforma lattes (foram quatro sessões) e um minicurso sobre normas de referências bibliográficas (em que discutimos softwares como EndNote, Mendeley e Zotero). As atividades ocorreram nos dias 21/10 (Módulo 1 citações e referências), 29/10 (Módulo 2 fichamento e referências), 11/11 (Módulo 3 mediações da produção escrita) e no dia 25/11 (Módulo 4 a produção da escrita científica e o plágio).

9 Para mais detalhes a esse respeito, ver as Tabelas 2 e 3 do editorial publicado no ano passado (Massimo, Gaio, Veneral e Almeida 2019). Além dessas duas tabelas, a descrição da implantação do Polo em Afuá na ilha do Marajó também auxilia a caracterizar esse ponto.

${ }^{10} \mathrm{O}$ relato do professor Marcos Baroncini Proença no "VI Seminário de Pesquisadores: as estratégias de pesquisa na pandemia”, sobre as pesquisas no biodigestor (uma rede colaborativa envolvendo as usinas da UFPR, e laboratório de bioenergia e biomassa da mesma instituição) sugere que é possível contornar dificuldades impostas pela de pesquisa em sentido estrito (como a coleta e a tabulação de dados). Tudo isso já estava estruturado para operar em meios virtuais antes da pandemia, mas essas rotinas acabaram sendo exacerbadas durante o isolamento social que a pandemia nos impôs. Qual é afinal a novidade?

A atividade de pesquisa requer disciplina, organização, e uma cuidadosa gestão do tempo, e durante a pandemia todos se viram obrigados a admitir em seus arquivos critérios para armazenar e recuperar vídeos e podcasts, e esse arquivamento acabou sendo favorecido pelos recursos do Univirtus que mencionamos acima.

Mas a novidade não fica restrita à migração compulsória para meios virtuais. Uma das maiores virtudes do EAD é a sua capilaridade. Apenas 1 a cada 5 estudantes do Grupo Uninter estão matriculados em Polos situados em capitais de estado, ou seja, cerca de $80 \%$ dos nossos estudantes do Grupo Uninter estão vinculados (ou habitam) em municípios do interior dos seus Estados ${ }^{9}$. Nessas condições, a iniciação científica precisa ter uma preocupação com a dimensão local. As pesquisas precisam fazer sentido em primeiro lugar para os estudantes do PIC. Com a pandemia, os pesquisadores passaram a dar mais ênfase para o uso de dados disponíveis em fontes secundárias, e os próprios gestores públicos passaram a ser interpelados com demandas que os obrigaram a entender a publicização dos dados como mecanismo para democratizar o acesso à informação, uma vez que dados públicos não pertencem aos governos, mas precisam estar disponíveis para a sociedade - o que é especialmente caro para os projetos de pesquisa vinculados aos cursos da área de saúde. Ainda sobre esse aspecto, a pandemia revelou que os indicadores presentes nas fontes secundárias seriam estéreis se os estudantes não fossem estimulados a interpretá-los com base na realidade da cidade ou no Estado onde vivem, ou seja, com base no significado dessas informações para a vida de cada estudante, e para a comunidade a qual ele pertence. Portanto, o isolamento social determinado pela pandemia ressaltou a importância da orientação individualizada, com a participação direta de mestres e doutores na orientação das pesquisas desenvolvidas no PIC - o que ficou bastante favorecido com o Univirtus Reuni. A grande quantidade de linhas e projetos de pesquisa (retratadas na Tabela 4) possibilita uma divisão de trabalho entre os professores, do que decorre uma orientação customizada aos jovens pesquisadores, para que a geração de conhecimento tenha efeito sobre formação da identidade profissional dos jovens pesquisadores.

Mas é claro que existem impactos negativos até mesmo em razão da necessidade, muitas vezes, de um ambiente adequado e estruturado. Os projetos de pesquisa que previam atividades em laboratórios tiveram que ser redesenhados. Os grupos se reuniram por meios virtuais, mas as pesquisas que exigiam trabalho de campo, com aplicação de questionários, precisaram rever a construção das suas amostras. Todas as atividades que requerem intervenção presencial tiveram que ser repensadas. Esses são problemas que afligem toda a comunidade acadêmica, e eles nos obrigam a reescrever protocolos, a reinventar processos, para que até mesmo as atividades que outrora ocorriam de modo presencial possam ser conduzidas na nuvem ${ }^{10}$.

Esse quadro permite dar uma ideia de como os pesquisadores da Uninter estão reagindo às restrições de isolamento impostas pela pandemia. Vejamos agora como os estudantes avaliam as medidas tomadas pela instituição ao longo de 2020.

Logo no começo do ano, uma série de medidas foram tomadas para preservar a saúde de toda a comunidade acadêmica do Centro Universitário Internacional Uninter. Uma das primeiras medidas foi a criação de Comitê de Operações de Emergência para o enfrentamento da epidemia de COVID-19. Esse comitê monitora as orientações fornecidas por organismos governamentais e 
restrição de acesso físico às instalações.

${ }^{11}$ O relatório na íntegra pode ser acessado em https://www.uninter.com/cpa/r esultado/pesquisa-sobre-a-atua cao-da-uninter-durante-a-epide mia-de-covid-19/ coordena todas as ações tomadas no âmbito da IES (Instituição de Ensino Superior) para o enfrentamento da COVID-19. As aulas que ocorriam na modalidade presencial passaram a ser realizadas dentro da plataforma Univirtus Reuni. As condições de trabalho para os docentes também foram severamente redesenhadas. Desde a segunda quinzena de março, todos os professores do Centro Universitário Uninter passaram a desenvolver suas atividades em teletrabalho. Os professores receberam kits contendo câmeras, microfones, e um banner para figurar no fundo das gravações das aulas, que passaram a ser realizadas de modo remoto. Essas medidas foram implantadas logo no início da Pandemia, e tão logo o novo padrão de trabalho remoto foi estabelecido, a Comissão Própria de Avaliação (CPA) passou a organizar a consulta com a apreciação dos estudantes acerca dessas novidades.

Os dados que discutiremos a seguir também estão disponíveis para consulta pública na página da Comissão Própria de Avaliação (CPA) da Uninter ${ }^{11}$. A pesquisa ocorreu entre os dias 01 e 06 de abril de 2020, e ela recolheu respostas de 39.404 pessoas, o que representa cerca de um quarto dos estudantes ativos da Uninter em 2020 naquele período. A Tabela 5 apresenta a representatividade da amostra, por modalidade de ensino.

Ao descrever a metodologia desta pesquisa, o relatório da CPA informa que o instrumento na modalidade EAD e Semipresencial foi composto de 22 questões, dividido em 6 blocos. As questões focaram na atuação da UNINTER durante a pandemia do COVID-19, buscando informações sobre o ambiente externo, a comunicação com os alunos, as medidas adotadas pelo Centro Universitário e o suporte ao meio acadêmico. No primeiro bloco, sobre o ambiente externo, o aluno poderia indicar apenas uma resposta, já no segundo bloco, ele tinha a disposição uma questão múltipla escolha e outras três onde ele podia mensurar o grau de satisfação a respeito da comunicação com a UNINTER. Nos três blocos seguintes, todas as questões eram de resposta única. Para esse editorial, vamos recuperar alguns dados que nos ajudem a caracterizar o perfil da amostra, para depois examinar as informações sobre a avaliação que os respondentes fizeram das medidas tomadas na Uninter.

Como a maior parte dos respondentes são alunos de cursos na modalidade $\mathrm{EAD}$, não surpreende que $96,2 \%$ possua acesso à internet. $3,3 \%$ dos respondentes indicaram possuir internet apenas pelo celular, e somente $0,5 \%$ relataram não possuir acesso à internet em suas residências seja por cabo, rádio ou linha telefônica (CPA 2020, p. 14). A maior parte dos respondentes possui conexão cuja velocidade varia entre $5 \mathrm{MB}$ e $50 \mathrm{MB}$ e a maioria dos alunos relatou realizar as atividades das disciplinas de seu curso por meio de notebooks (CPA 2020, p. 15). Ainda para caracterizar as condições desses estudantes, observamos no Gráfico 1 que os respondentes (e a maior parte dos seus familiares) estavam realizando o isolamento social quando a enquete foi realizada.

Tabela 5 - Composição e representatividade da amostra, por modalidade

\begin{tabular}{lccc}
\hline Modalidade* & Alunos Ativos & Participantes & Representatividade \\
\hline Presencial & 1.358 & 411 & $30,3 \%$ \\
Semipresencial & 2.404 & 437 & $18,2 \%$ \\
Ensino à distância & 156.223 & 38.191 & $24,4 \%$ \\
Pós-Graduação & 829 & 365 & $44,0 \%$ \\
Total & 160.814 & 39.404 & $24,5 \%$ \\
\hline
\end{tabular}

Fonte: Comissão Própria de Avaliação (https://www.uninter.com/cpa/).

* No caso da pós-graduação, houve respondentes somente nos cursos da modalidade EAD. 
Gráfico 1 - Alcance do isolamento social entre os alunos da Uninter

\section{Você e as pessoas de sua família que moram com você, estão realizando isolamento social?}

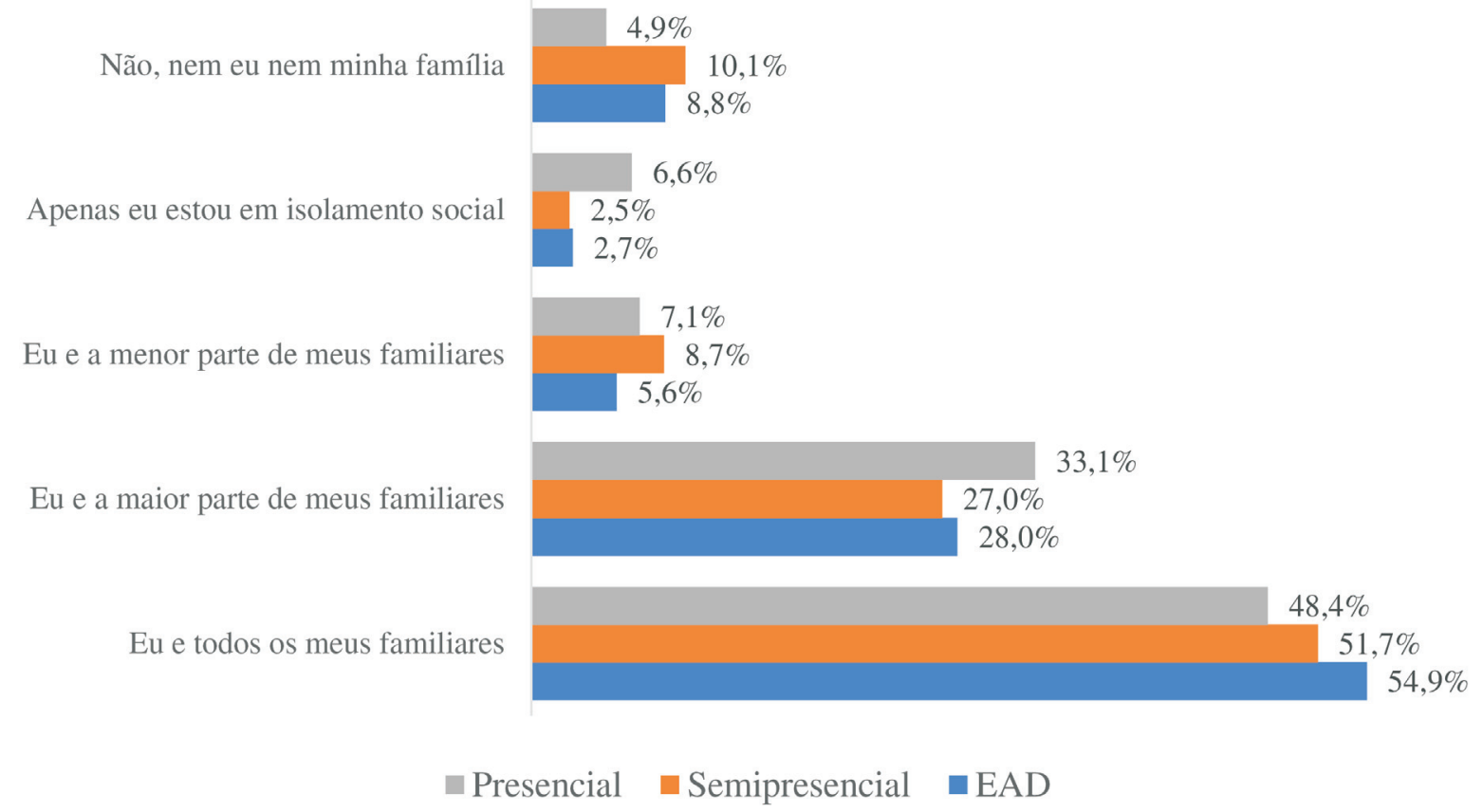

Fonte: Comissão Própria de Avaliação (https://www.uninter.com/cpa/).

A Tabela 6 apresenta os resultados do indicador de satisfação obtido com a aplicação do questionário. Os dados presentes na Tabela 6 revelam indicadores de satisfação mais elevados entre os estudantes dos cursos na modalidade EAD. $\mathrm{O}$ indicador mais baixo aparece na percepção dos estudantes do presencial, e está relacionado com as aulas por meio de conferências. Os ajustes no calendário das avaliações também foram considerados nesse questionário, e como esperado, eles foram percebidos como satisfatórios pelos estudantes.

O último dado que desejamos ressaltar nesse editorial está relacionado com o suporte fornecido pelos docentes e pelas demais equipes de apoio aos estudantes durante a pandemia. Os valores aparecem na Tabela 7. Esses resultados revelam que os estudantes dos cursos na modalidade presencial possuem indicadores de satisfação claramente inferiores se comparados com a satisfação do suporte fornecido aos estudantes das modalidades semipresencial e EAD (muito embora os percentuais de respondentes que não possuem condições de responder também sejam elevados nas três modalidades).

A realização dessa pesquisa com os estudantes tem como objetivo subsidiar o acompanhamento, decisão e ação dos gestores. Esse é um importante mecanismo para consolidar protocolos de auto avaliação e monitoramento do processo de ensino no âmbito das Instituições de Ensino Superior (IES). De acordo com Sanchez, Sanchez e Albertin "Gestores têm enfrentado a necessidade de decidir sobre como otimizar as novas oportunidades de produção de ofertas educacionais com os variados níveis de autonomia que o Ensino a Distância (EaD) permite" (Sanchez et al., 2015, p.512). Entre essas novas oportunidades é possível incluir a consulta com os estudantes acerca do modo como eles avaliaram as medidas tomadas em face da pandemia, utilizando para essa consulta os meios disponíveis nas mesmas plataformas em que ocorre o EAD. 
Tabela 6 - Percepção dos estudantes quanto às medidas tomadas pela UNINTER

\begin{tabular}{|c|c|c|c|c|c|c|}
\hline & \multicolumn{2}{|c|}{ Presencial } & \multicolumn{2}{|c|}{ Semi Presencial } & \multicolumn{2}{|c|}{ EAD } \\
\hline & $\begin{array}{l}\text { Indicador de } \\
\text { Satisfação }\end{array}$ & $\begin{array}{l}\text { Não tenho } \\
\text { condições de avaliar }\end{array}$ & $\begin{array}{l}\text { Indicador de } \\
\text { Satisfação }\end{array}$ & $\begin{array}{c}\text { Não tenho } \\
\text { condições de avaliar }\end{array}$ & $\begin{array}{l}\text { Indicador de } \\
\text { Satisfação }\end{array}$ & $\begin{array}{c}\text { Não tenho } \\
\text { condições de avaliar }\end{array}$ \\
\hline $\begin{array}{l}\text { Qual sua opinião sobre a medida da UNIN- } \\
\text { TER de criar um Comitê de Operações de } \\
\text { Emergência para o enfrentamento da } \\
\text { epidemia de COVID-19? }\end{array}$ & 8,8 & $7,3 \%$ & 8,9 & $3,0 \%$ & 9,0 & $7,4 \%$ \\
\hline $\begin{array}{l}\text { Como você entende a decisão da UNIN- } \\
\text { TER de suspender a realização das } \\
\text { atividades presenciais no Campus?* }\end{array}$ & 9,0 & $1,7 \%$ & & & & \\
\hline $\begin{array}{l}\text { Qual sua avaliação sobre a realização das } \\
\text { aulas das disciplinas, por meio da ferra- } \\
\text { menta de conferência da UNINTER?* }\end{array}$ & 6,5 & $1,0 \%$ & & & & \\
\hline $\begin{array}{l}\text { Como você entende a decisão da UNIN- } \\
\text { TER de adiar para } 17 \text { de abril a realização } \\
\text { das atividades presenciais tais como pro- } \\
\text { vas, apresentações de trabalhos, atividades } \\
\text { de laboratórios.** }\end{array}$ & & & 8,8 & $4,6 \%$ & 9,0 & $3,1 \%$ \\
\hline $\begin{array}{l}\text { Você avalia como a prorrogação da entrega } \\
\text { da APOL } 01 \text { para } 30 \text { de março?** }\end{array}$ & & & 8,6 & $15,8 \%$ & 8,9 & $4,4 \%$ \\
\hline $\begin{array}{l}\text { Qual sua avaliação sobre a medida da } \\
\text { UNINTER, de permitir a realização de } \\
\text { PROVAS ONLINE, sem a necessidade de } \\
\text { ir ao Polo, nesse período de epidemia de } \\
\text { COVID-19?** }\end{array}$ & & & 8,9 & $2,1 \%$ & 9,1 & $1,6 \%$ \\
\hline $\begin{array}{l}\text { Como você avalia a extensão para } 30 \text { de } \\
\text { Abril, do período para a realização das } \\
\text { provas da Fase I do Módulo A?** }\end{array}$ & & & 9,0 & $9,8 \%$ & 9,2 & $3,0 \%$ \\
\hline
\end{tabular}

Fonte: Comissão Própria de Avaliação (https://www.uninter.com/cpa/).

*Obs.: a questão foi apresentada somente para alunos da modalidade Presencial.

**Obs.: a questão foi apresentada somente para alunos das modalidades Semipresencial e EAD. 


\begin{tabular}{|c|c|c|c|c|c|c|}
\hline & \multicolumn{2}{|c|}{ Presencial } & \multicolumn{2}{|c|}{ Semi Presencial } & \multicolumn{2}{|c|}{ EAD } \\
\hline & $\begin{array}{l}\text { Indicador de } \\
\text { Satisfação }\end{array}$ & $\begin{array}{c}\text { Não tenho condições } \\
\text { de avaliar }\end{array}$ & $\begin{array}{l}\text { Indicador de } \\
\text { Satisfação }\end{array}$ & $\begin{array}{c}\text { Não tenho condições } \\
\text { de avaliar }\end{array}$ & $\begin{array}{l}\text { Indicador de } \\
\text { Satisfação }\end{array}$ & $\begin{array}{c}\text { Não tenho condições } \\
\text { de avaliar }\end{array}$ \\
\hline $\begin{array}{l}\text { Como você avalia as ações específicas de } \\
\text { seu CURSO para favorecer a realização de } \\
\text { seus estudos nesse período? }\end{array}$ & 7,3 & $4,1 \%$ & 8,3 & $3,0 \%$ & 8,7 & $5,7 \%$ \\
\hline $\begin{array}{l}\text { Caso você tenha entrado em contato com a } \\
\text { TUTORIA ON-LINE de seu Curso, para } \\
\text { tratar de alguma situação decorrente da } \\
\text { epidemia de COVID-19, como você avalia } \\
\text { o atendimento recebido?* }\end{array}$ & 7,5 & $57,4 \%$ & 8,0 & $49,4 \%$ & 8,5 & $50,3 \%$ \\
\hline $\begin{array}{l}\text { Se você entrou em contato com a Central } \\
\text { de Mediação Acadêmica - CMA, para tratar } \\
\text { de alguma situação decorrente da epidemia } \\
\text { de COVID-19, como você avalia o atendi- } \\
\text { mento recebido?* }\end{array}$ & 7,6 & $69,3 \%$ & 8,1 & $62,7 \%$ & 8,5 & $58,8 \%$ \\
\hline $\begin{array}{l}\text { Caso você tenha entrado em contato com o } \\
\text { POLO onde está matriculado, para tratar de } \\
\text { alguma situação decorrente da epidemia de } \\
\text { COVID-19, como você avalia o atendimen- } \\
\text { to recebido?** }\end{array}$ & & & 7,7 & $56,1 \%$ & 8,7 & $41,6 \%$ \\
\hline
\end{tabular}

Fonte: Comissão Própria de Avaliação (https://www.uninter.com/cpa/).

*Obs.: a questão foi apresentada somente para alunos da modalidade Presencial.

**Obs.: a questão foi apresentada somente para alunos das modalidades Semipresencial e EAD. 
Com a difusão de novas tecnologias de informação, "observamos com mais atenção as relações entre conhecimento, tecnologia e ensino-aprendizagem (...) Torna-se, assim, um grande desafio para os educadores perceberem que as relações que se conectam à aprendizagem transcendem as salas de aula convencionais e se aproximam, cada vez mais, das experiências individuais vividas na diversidade das linguagens tecnológicas, e também daquilo que chamamos de grupos sociais" (França 2009, p.56).

Nesse contexto, a avaliação dos próprios alunos é uma informação estratégica. Ao tomar como base as percepções dos estudantes para monitorar a qualidade do EAD, os gestores das IES podem dar um passo importante para a oferta de um ensino em que os indivíduos se sintam de fato sujeitos de seu processo de aprendizagem. Isso é tanto mais importante à medida em que "estamos assistindo ao nascimento de uma geração de jovens inovadores, antenados, entendedores do poder da mídia, que aprendem por meio da interação. A informação não é apenas consumida. Ela também é produzida pelos jovens. [...] esses jovens têm autoconfiança e autoestima. Sabem que seu futuro não está nas mãos de governos ou empresas. Valorizam os direitos individuais, como a privacidade e a liberdade de expressão. E mais: querem ser tratados com justiça”. (Bohadana \& Valle 2009, p.563).

Essas considerações nos auxiliam a delimitar a importância de indicadores objetivos obtidos com base em questionários como os elaborados na Comissão Própria de Avaliação (CPA). Trata-se de mobilizar não apenas a infraestrutura do Ambiente Virtual de Aprendizagem (que permite a consulta com todos os estudantes vinculados aos cursos), mas sobretudo, trata-se de formalizar nessas plataformas eletrônicas protocolos de consulta com os alunos, construindo bases de dados coletadas de modo sistemático, que permitam, através de indicadores mensuráveis, aperfeiçoar o acompanhamento, a tomada de decisão e ação dos gestores. Assim, "do ponto de vista dos gestores de instituições de ensino, o desenvolvimento dessa modalidade torna-se, portanto, uma decisão de busca pela eficiência. Usar recursos adequadamente para maximizar o atendimento aos objetivos consiste em identificar quais os meios mais adequados para veicular os materiais, de acordo com o perfil dos alunos". (Sanchez et al., 2015, p.524).

$$
* * *
$$

As informações que discutimos ao longo deste editorial nos permitem estabelecer três conclusões.

A primeira conclusão está relacionada com a importância da velocidade com que as ações foram tomadas, logo após de declarada a pandemia. Por sermos uma instituição de referência no EAD, a transição dos processos se tornou mais ágil uma vez que a grande maioria da nossa comunidade acadêmica já estava familiarizada com as rotinas da EAD. O apoio da instituição, fornecendo toda a infraestrutura necessária para manter as atividades acadêmicas em pleno funcionamento foi vital para assegurar a saúde de todos os profissionais e estudante da Uninter. Verificou-se também a importância da Central de Mediação Acadêmica, que prima por um atendimento humanizado, que passe tranquilidade e diretrizes aos estudantes para que se sintam seguros e amparados pelo Centro Universitário Internacional Uninter.

A segunda conclusão refere-se à centralidade que o Programa de Iniciação Científica da Uninter adquire na formação dos estudantes de graduação. Os programas de iniciação científica podem ser um mecanismo eficaz para socializar os estudantes de graduação nos códigos, valores e condutas que são peculiares ao universo acadêmico. Essa é uma característica do PIC que se aplica para qualquer instituição de ensino superior, mas no caso dos cursos de gra- 
duação ofertados na modalidade EAD esse traço do PIC é ainda mais relevante, devido à impessoalidade que é própria desta modalidade de ensino (uma vez que as interações ocorrem apenas por meios virtuais). Como vimos acima, as dinâmicas da pesquisa sofreram impactos diretos com a pandemia de COVID19, e o PIC pode ser um espaço para que os estudantes atuem como sujeitos do seu processo de ensino e aprendizagem, e participem de modo ativo na reconfiguração das rotinas de trabalho que a pandemia impôs aos pesquisadores.

A terceira conclusão está relacionada com a percepção dos estudantes acerca das medidas tomadas diante da pandemia de COVID-19. Vimos que a maior parte dos estudantes e seus familiares estavam, em abril de 2020, em condições favoráveis para observar o isolamento social (uma vez que essa é, atualmente, a única medida reconhecidamente eficaz para prevenir essa doença). Vimos também que os estudantes do EAD possuem uma avaliação mais favorável acerca dessas medidas do que os estudantes do presencial. Essa situação revela que a transição para o ensino remoto não é algo simples e automático, nem mesmo em uma instituição como a Uninter, com toda a gama de recursos disponíveis no ambiente virtual de aprendizagem. A comunidade acadêmica brasileira se viu obrigada a utilizar meios remotos para manter suas rotinas durante o período de isolamento. Essa transição precisa estar acompanhada de consultas com os estudantes, pois sem ela a posição dos gestores, para conduzir os processos de tomada de decisão, ficaria bastante fragilizada.

A pandemia de COVID-19 impôs à comunidade universitária desafios das mais diversas ordens. Esperamos que esse documento possa ter alguma utilidade para que os editores de outros periódicos possam construir novos modelos de financiamento à comunicação científica, mas sobretudo, esperamos que a experiência acumulada no Centro Universitário Internacional Uninter contribua para o enfrentamento das contingências impostas pelo isolamento social em que nos encontramos desde o início de 2020.

Lucas Massimo (LUCAS.SO@uninter.com) é coordenador de cursos de graduação no Centro Universitário Internacional Uninter e editor da Revista de Sociologia e Política.

Benhur Gaio (BENHUR.G@uninter.com) é reitor do Centro Universitário Internacional Uninter.

Nelson Pereira Castanheira (NELSON.C@uninter.com) é Pró-Reitor de Pós-Graduação, Pesquisa e Extensão do Centro Universitário Internacional Uninter.

Débora Veneral (DEBORA.V@uninter.com) é diretora da Escola Superior de Gestão Pública, Política, Jurídica e Segurança do Centro Universitário Internacional Uninter.

\section{Referências}

Bohadana, E. \& Valle, L. DO. (2009) O quem da educação a distância. Revista Brasileira de Educação, 14(42), pp. 551-564. DOI: $10.1590 / \mathrm{S} 1413-24782009000300011$

França, G. (2009) Os ambientes de aprendizagem na época da hipermídia e da Educação a Distância. Perspectivas em Ciência da Informação, 14(1), pp. 55-65, 2009. DOI: 10.1590/S1413-99362009000100005

Comissão Própria de Avaliação (CPA) do Centro Universitário Internacional - UNINTER (2020) Relatório Gerencial Pesquisa sobre a atuação da Uninter durante a epidemia de covid-19. Curitiba: CPA, 35p. Disponível em: $<$ https://www.uninter.com/cpa/resultado/pesquisa-sobre-a-atuacao-da-uninter-durante-a-epidemia-de-covid-19/>. Acesso em: 06 de nov. 2020.

Grupo UNINTER, 2020 (21 out) Minicurso Normas ABNT: Módulo 1 Citações e Referências Coordenação de Pesquisa [vídeo]. Youtube. Disponível em <https://youtu.be/Whi9amLTmd8>. Acesso em: 12 de nov. 2020.

Grupo UNINTER, 2020 (28 out) VI Seminário de Pesquisadores: as estratégias de pesquisa na pandemia Coordenação de Pesquisa [vídeo]. Youtube. Disponível em <https://youtu.be/rdBOTp6brUE>. Acesso em: 12 de nov. 2020.

Grupo UNINTER, 2020 (29 out) Minicurso Normas ABNT: Módulo 2 Fichamento e Referências Coordenação de Pesquisa [vídeo]. Youtube. Disponível em <https://youtu.be/FhQHvkEPF7E>. Acesso em: 12 de nov. 2020. 
Grupo UNINTER, 2020 (11 nov) Minicurso Normas ABNT: Módulo 3 Mediações da Produção Escrita Coordenação de Pesquisa [vídeo]. Youtube. Disponível em <https://youtu.be/tHumR1RsQ4o>. Acesso em: 12 de nov. 2020.

Grupo UNINTER, 2020 (25 nov) Minicurso Normas ABNT: Módulo 4 A produção da escrita científica e o plágio Coordenação de Pesquisa [vídeo]. Youtube. Disponível em <https://youtu.be/TqEaItAvu5s>. Acesso em: 26 de nov. 2020.

Massimo, L.; Gaio, B.; Veneral, D. \& Almeida, S. (2019). Editorial: A parceria entre a Revista de Sociologia e Política e o Centro Universitário Internacional Uninter.Revista de Sociologia e Política,27(69), pp. 1-9. DOI: $10.1590 / 1678-987319276900$

Sanchez, L. H. A.; Sanchez, O. P.; Albertin, A. L. (2015) Gestão de recursos do EAD: como adequar as tecnologias aos perfis de assimilação. Revista de Administração de Empresas, 55(5) pp. 511-526, 2015. DOI: 10.1590/S0034-759020150504

This is an Open Access article distributed under the terms of the Creative Commons Attribution Non-Commercial License which permits unrestricted non-commercial use, distribution, and reproduction in any medium provided the original work is properly cited.

A produção desse manuscrito foi viabilizada através do patrocínio fornecido pelo Centro Universitário Internacional Uninter à Revista de Sociologia e Política. 